\title{
О НЕКОТОРЫХ ПРОТИВОРЕЧИЯХ В ОТНОШЕНИЯХ РАСПРЕДЕЛЕНИЯ РЕЗУЛЬТАТОВ ТРУДА
}

\section{SOME TENSIONS IN DISTRIBUTION DELIVERABLES RELATIONS}

V. Rylov

Summary. The paper reviews relations between a holder of means of production and employee in-process of production and distribution produced prosperity. The paper allocated three aspects of the production process (government, a holder of means of production and employee), set out reasons for participation in the production process. Also tried to reflect basis of different relation of the participants in the production process to distribution deliverables.

Keywords: distribution deliverables, capitalism, employee, holder of means of production, productive relations, balance of distribution produced prosperity.

\author{
Рылов Василий Александрович \\ Начальник Земельно-имущественного управления, \\ ФГАОУ ВО «Казанский (Приволжский) федеральный \\ университет» \\ rv-1975@mail.ru
}

Аннотация. Статья затрагивает отношения, возникающие между собственником средств производства и наемным работником в процессе производства и распределения произведенных благ. В работе выделены три стороны процесса производства (государство, собственник средств производства и наемный работник), изложены мотивы, побуждающие к участию в процессе производства. Также предпринята попытка осмыслить основу различного отношения участников процесса производства к распределению результатов труда.

Ключевые слова: распределение результатов труда, капитализм, наемный работник, собственник средств производства, производственные отношения, баланс распределения произведенных благ.

всегда гарантируется и контролируется усилиями государства. Из изложено выше следует, что в производстве любого блага, в последующем предназначенного для распределения, участвуют три субъекта: рабочая сила (носитель - наемный работник), капитал (владелец собственник средств производства), сформированные необходимые условия (обладатель права - государство). Выражение - «сформированные необходимые условия» применено лишь для лаконичности изложения и подразумевает собой всю многообразную систему государственного устройства, влияющую на процесс производства (такие функции и системы государства как фискальная, контролирующая, монетарная, протекционистская так же имеются в виду).

После того как благо произведено и реализовано каждый участник процесса производства претендует на часть дохода (наемный работник за свою использованную рабочую силу, собственник средств производства за затраченный на процесс производства капитал, государство за затраты понесенные им в период производства блага).

Упрощённо, процесс производства и распределения можно представить в виде схемы (рис. 1).

Как уже упоминалось выше, цель нашей работы мы видим в поиске противоречий в отношениях между наемным работником и собственником средств производ- 
Таблица 1. Основные фонды по формам собственности (млрд. руб.)

\begin{tabular}{|l|l|l|l|l|l|}
\hline \multicolumn{1}{|l|}{} & 1990 & \multicolumn{2}{l|}{$\mathbf{2 0 1 7}$} \\
\hline Основные фонды, всего: & 2958 & $100 \%$ & 194649,464 & $100 \%$ \\
\hline \multicolumn{1}{|l|}{ в том числе: } & 2624 & $88,8 \%$ & 42822,882 & $22 \%$ \\
\hline Государственная собственность & 334 & $11,2 \%$ & 151826,582 & $78 \%$ \\
\hline Не государственная собственность
\end{tabular}

Источник: Народное хозяйство СССР в 1990 г.; Статистический ежегодник/Госкомстат СССР.-М.: Финансы и статистика, 1991. (стр.- 291), официальный сайт статистики России: http://gks.ru, дата обращения 21.03.2019 (вкладка «основные фонды»)

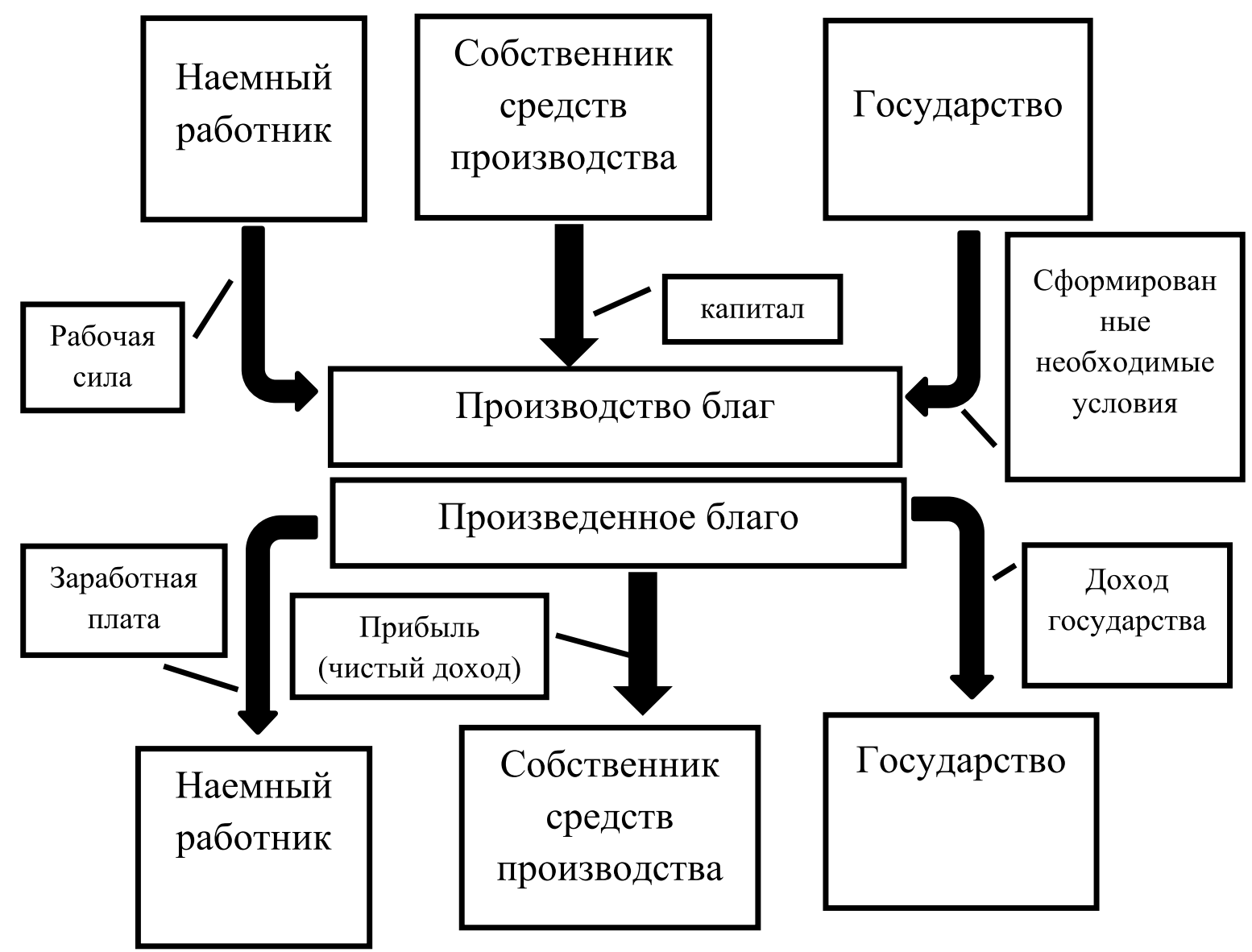

Рис. 1

ства в вопросах распределения результатов труда, если таковые имеются. Как видно из схемы, представленной выше в производство и распределение блага вовлечены три стороны, каждая из которых вносит необходимый вклад и получает часть произведенного. Соответственно, если и существуют какие-либо противоречия возникающие в процессе распределения произведенных благ, между наемными рабочими и собственниками средств производства, то они не расположены в области производственных отношений, а их поиск должен проходить в части определения долей, внесенных в процесс производства и долей, полученных в ходе распределения.
Такая схема функционировала в России не всегда. В дореформенный (социалистический) период развития страны средства производства в основе своей принадлежали государству. Население работало по найму, получало установленную часть дохода в виде регламентированной заработной платы. Практически отсутствовала частная собственность на средства производства. Поэтому не возникало отношений между капиталистом и наемным работником.

В России начала 21 века капитал сменил собственника. В дореформенной стране большая часть основных 
Таблица 2. Средняя заработная плата, начисленная в России (по формам собственности), в руб.

\begin{tabular}{|l|l|l|}
\hline Форма собственности & $\mathbf{2 0 1 5}$ & $\mathbf{2 0 1 6}$ \\
\hline Государственная & 37312 & 39312 \\
\hline Частная & 30026 & 32664 \\
\hline
\end{tabular}

Источник: официальный сайт статистики России: http://gks.ru, дата обращения 06.06.2019 (вкладка «труд и занятость в России.2017.», стр. 226)

Таблица 3. Распределение ВВП в млн. руб.

\begin{tabular}{|l|l|l|l|}
\hline $\begin{array}{l}\text { Валовый внутренний продукт, } \\
\text { всего }\end{array}$ & $\mathbf{2 0 1 4}$ & $\mathbf{2 0 1 5}$ & $\mathbf{2 0 1 6}$ \\
\hline $\begin{array}{l}\text { из него оплата труда наемных } \\
\text { рабочих }\end{array}$ & 37387176,4 & 83232618,4 & 86043648,9 \\
\hline $\begin{array}{l}\text { из него налоги на производство } \\
\text { и импорт }\end{array}$ & 11497947,1 & 38091452,2 & 40779288,6 \\
\hline $\begin{array}{l}\text { из него валовая прибыль } \\
\text { экономики и иные доходы }\end{array}$ & 30808241,9 & 9787221,3 & 9937267,5 \\
\hline $\begin{array}{l}\text { Доля оплаты труда наемных } \\
\text { работников в ввп,\% }\end{array}$ & 47,2 & 35868474,6 & 35851105,2 \\
\hline Доля налогов в ввп,\% & 14,5 & 45,7 & 47,3 \\
\hline $\begin{array}{l}\text { Доля валовой прибыли в ввп } \\
\text { (с учетом субсидий),\% }\end{array}$ & 38,9 & 11,7 & 11,5 \\
\hline
\end{tabular}

Источник: официальный сайт статистики России: http://gks.ru, дата обращения 11.06.2019

(вкладка «национальные счета России в 2011-2016 годах», стр. 23)

фондов принадлежала государству, после проведения реформ, государственным остается лишь 22\% всех основных фондов страны. (см. таблицу 1).

Тем не менее, по состоянию на 2017 год на предприятиях негосударственной формы собственности задействовано 26970 тыс. человек, что составляет 61\% от общей численности занятых на предприятиях. При этом всего в России по данным на 2017 год занято в экономике 71843 тыс. человек'. То есть, количество наемных работников, осуществляющих деятельность в частных организациях, составляет 37,5\% от общего числа занятых в стране.

Следует отметить, что частный капитал не превалирует на рынке труда, тем не менее, имея существенную долю, оказывает прямое влияние на его развитие. При этом частный капитал аккумулирует 78\% всех основных фондов страны. Иными словами, 37,5\% наемных работников задействованы в труде с использованием 78\% всех основных средств, не принадлежащих государству, и $62,5 \%$ наемных работников используют $22 \%$ основных средств страны, принадлежащих государству. Соответ-

\footnotetext{
Источник: сборник «Российский статистический ежегодник.2018», стр. 112, размещен на Сайт официальной статистики http://www.gks.ru, дата обращения 25.08.2019
}

ственно, основным работодателем в стране остается государство. При этом, государство оплачивает труд выше, в среднем на 17-20\%, чем предприятия с негосударственными активами. (см. таблицу 2$)$.

Сложность в изучении отношений «работодатель наемный рабочий», их экономической части, состоит в определении измеримых показателей, в которых может быть выражена оптимальное распределение долей полученного результата труда.

Видимая часть конфликта интересов, в официальной статистике, представлена лишь показателем «количество забастовок», основной задачей которых являлось повышение уровня оплаты за труд. В период с 2014 по 2016 год в России официально зарегистрировано 10 забастовок, в которых приняло участие 1,4 млн. человек ${ }^{2}$. Данная статистика не может использоваться в анализе и не дает понимания сложившейся ситуации. Поэтому, в целях визуализации конфликта, рассмотрим каким образом распределяется между наемным работником и работодателем произведенный продукт. (см. таблицу 3).

2 Источник: Труд и занятость в России. 2017: Стат.сб./Росстат Т78 М., 2017. 261 с.- стр. 155. Размещен на официальном сайте статистики http://gks.ru 
Таблица 4. Оплата труда и валовая прибыль предприятий в России

\begin{tabular}{|c|c|c|c|}
\hline & 2015 & 2016 & 2017 \\
\hline Оплата труда, всего, в млн. руб. & 38697771,5 & 40941461,9 & 43904226,5 \\
\hline Валовая прибыль, всего, в млн. руб. & 35418918,4 & 35786247,6 & 38178 160,7 \\
\hline
\end{tabular}

Информация представлена автором на основании источника: официальный сайт статистики России:

http://gks.ru, дата обращения 11.12.2019 (вкладка «приложение к ежегоднику»)

Таблица 5. Распределение населения по величине доходов (в \% к итогу) в 2018 году

\begin{tabular}{|l|l|}
\hline Все население,\% & 100 \\
\hline В том числе со среднедушевым денежным доходом: ниже 7 000 руб. & 5,1 \\
\hline $7001-10000$ & 7,1 \\
\hline $10001-14000$ & 11,2 \\
\hline $14001-19000$ & 13,8 \\
\hline $27001-27000$ & 18,1 \\
\hline $45001-60000$ & 23,6 \\
\hline свыше 60000 & 9,2 \\
\hline
\end{tabular}

Информация подготовлена автором на основании источника: Сайт официальной статистики http://www.gks.ru, вкладка «Россия в цифрах.2019» стр. 125 дата обращения 12.11.2019

В период с 2014 по 2016 годы валовый продукт в России составлял от 79 до 86 трлн. рублей, из которых на оплату наемного труда направлялось от 45,7 до 47,3\%, валовая прибыль же составила от 38,9 до 43,1\%. Как видим, большая часть валового продукта распределяется на оплату труда наемных рабочих. Необходимо отметить, что оплата труда является основным источником дохода населения и составляет $65 \%$ от всех получаемых населением доходов ${ }^{1}$. Иными словами, наемный работник (в обобщенном понимании), заинтересован в успешном развитии производства, так как заработная плата составляет основу его дохода.

Как известно, основной мотивацией развития производства у капиталиста является получение максимальной прибыли. Основной же задачей наемного работника является получение максимальной заработной платы. Объем заработной платы регламентирован трудовым договором, объем прибыли не регламентирован и может составлять любую величину. Ходя задачи капиталиста и наемного работника в ходе участия в производстве различны, никто из них не заинтересован в свертывании или ограничении процесса производства. Статистика показывает, что рост прибыли и рост затрат на оплату труда параллелен (см. таблицу 4).

Если экономические механизмы срабатывают таким образом, что рост прибыли сопровождается ростом за-

${ }^{1}$ Источник: Сборник «Россия в цифрах.2018», стр. 122, размещен на Сайте официальной статистики http://www.gks.ru, дата обращения 25.03.2019 трат на оплату труда, необходимость их трансформации не очевидна. Как известно, оплачивает труд работодатель. Возможно, механизмы распределения заработной платы содержат элементы конфликта отношений между наемным рабочим и работодателем. (см. таблицу 5).

Информация, представленная выше свидетельствует о том, что весь объем выплачиваемой заработной платы распределяется не равномерно. При этом, как отмечено выше, основным работодателем в стране остается государство, которое держит уровень оплаты труда в среднем на 17-20\% выше, чем заработные платы, получаемые наемными работниками у частных работодателей. Ранее, при плановой системе хозяйствования, устанавливались «тарифные сетки», которые определили единую систему формирования оплаты труда в стране, при этом основным параметром, влияющим на оплату труда, являлась квалификация сотрудника. [Источник: Статистический ежегодник «Народное хозяйство СССР в 1990 г» стр. 40-44] При переходе на рыночную систему хозяйствования основным показателем формирующим способность хозяйствующего субъекта платить определенную заработную плату становиться рентабельность, его эффективность, не зависимо от формы собственности. Соответственно, дифференциация опыты труда на предприятиях и организациях является в том числе результатом всесторонней конкуренции, иначе, проявлением результатов рыночного хозяйствования. А такие результаты, как сказано выше, являются следствием совместных усилий собственника капитала и наемного работника. Поэтому при распределении установленного 
Таблица 6. Объем потребления за счет средств от оплаты труда, кредитов и иных источников

\begin{tabular}{|c|c|c|c|c|c|c|c|c|}
\hline & 2010 & 2011 & 2012 & 2013 & 2014 & 2015 & 2016 & 2017 \\
\hline Отношение оплаты труда к ВВП & $50 \%$ & $44 \%$ & $44 \%$ & $46 \%$ & $47 \%$ & $46 \%$ & $48 \%$ & $48 \%$ \\
\hline $\begin{array}{l}\text { Отношение объема выданных } \\
\text { кредитов к ВВП }\end{array}$ & $8,8 \%$ & $9,2 \%$ & $11,4 \%$ & $13,6 \%$ & $14,3 \%$ & $12,8 \%$ & $12,5 \%$ & $13,2 \%$ \\
\hline $\begin{array}{l}\text { Отношение конечного } \\
\text { потребления за счет иных } \\
\text { источников к ВВП }\end{array}$ & $11,2 \%$ & $14,8 \%$ & $13,6 \%$ & $11,4 \%$ & $9,7 \%$ & $11,2 \%$ & $10,5 \%$ & $8,8 \%$ \\
\hline $\begin{array}{l}\text { Отношение конечного } \\
\text { потребления к ВВП }\end{array}$ & $70 \%$ & $68 \%$ & $69 \%$ & $71 \%$ & $71 \%$ & $70 \%$ & $71 \%$ & $70 \%$ \\
\hline
\end{tabular}

Информация подготовлена автором на основании источника: Сайт официальной статистики http:// www.gks.ru, вкладка «приложение к ежегоднику», дата обращения 31.07.2019

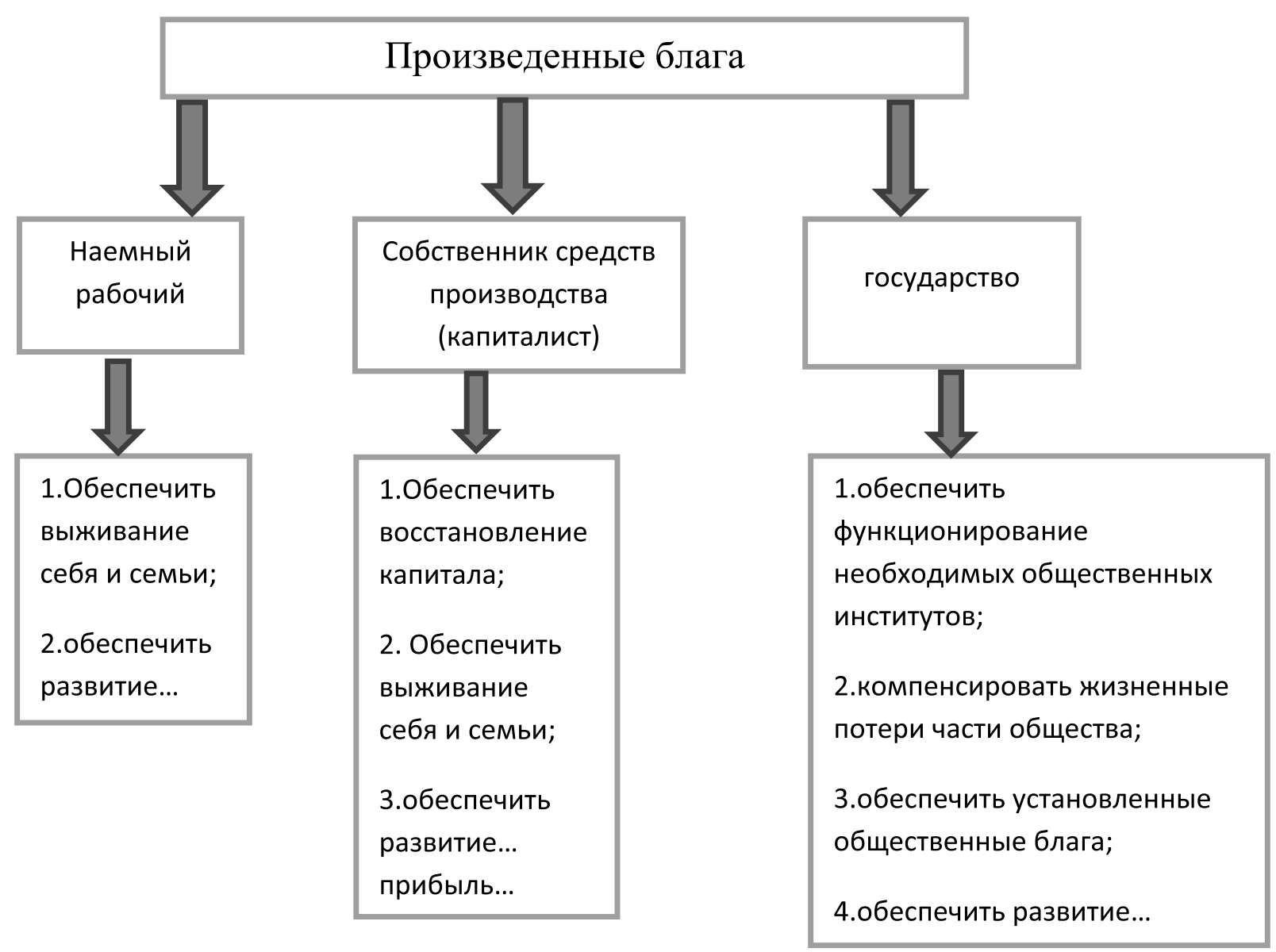

Рис. 2. Основные мотивы деятельности участников процесса производства и распределения благ

(выделенного) объема оплаты труда работодатель не заинтересован в нарушении интересов наемного работника, так как последний принимает непосредственное участие в формировании конкурентоспособности первого.

И так, возможности капиталиста выделять на оплату труда наибольший объем средств ограничиваются рыночными механизмами. При этом капиталист должен понимать, что основой его благосостояния в условиях капиталистического производства является потребление производимой им продукции. Соответственно, чем больше общество потребляет, тем быстрее возрастает доход капиталиста (собственника средств производства). Зависимость капиталиста от потребления наемного работника приведена в таблице 6.

Как видно из представленных данных, конечное потребление производится в среднем более чем на $60 \%$ 
за счет средств, формирующих оплату труда. Потребление за счет доходов от капитала и заимствования не превышает $40 \%$ от всего конечного потребления. Основываясь на вышеизложенном, капиталист может формировать рынок сбыта тремя способами: формирую соответствующую оплату труда наемных работников, стимулировать кредитование (заимствование), способствовать потреблению за счет доходов от капитала, последнее сопряжено с развитием конкуренции. Потребление за счет кредитования, как показывает практика, не безгранично. Поэтому капиталист не имеет экономической заинтересованности в ухудшении уровня жизни наемных работников, более того он хочет иметь на производстве только лучший, а потому наиболее востребованный, (соответственно высокооплачиваемый) персонал.

Однако, существующие реалии рынка, отраслевая конкурентоспособность производства, принадлежащего капиталисту, внедренные на производстве технологии, влияющие на энергоэффективность и потребление сырья, уровень организации труда вносят соответствующие коррективы в его, капиталиста, возможность поддерживать наиболее высокий уровень оплаты труда.

Каждый наемный работник, объективно, стремиться получать наиболее высокую оплату труда. Тем не менее, его желание ограничивается его вкладом в обобществленный результат того или иного производства, а также рентабельностью предприятия, на котором он работает. Необходимо отметить, что далеко не всегда доход, полученный от усилий наемного работника, зависит от его компетенций и его вклада в производство блага. В таком случае возникает диссонанс, который, в зависимости от ситуации на рынке труда, приводит к смене работодателя.

Из вышеизложенного не следует понимания противоречий в отношениях собственника средств производства и наемного рабочего в вопросах распределения произведенных благ. Оба этих субъекта заинтересованных в развитии производства, оба ставят своей целью получения максимального дохода, оба принимают участие в государственном строительстве путем передачи части своего дохода в государственную казну, оба получают часть произведенного блага, в той или иной степени определенную (ограниченную) рыночными реалиями. Возможно, причина таких противоречий может находиться в контексте целеполагания деятельности. Важной является первопричина побуждающая субъекта производственных отношений принимать в них участие. (см. схему на рис. 2).

Данная схема представляет собой наиболее общее понимание нами экономических мотивов хозяйствен- ной деятельности участников процесса производства и распределения (приоритеты выставлены по принципу первостепенности). Представленная схема сознательно упрощена и необходима лишь для того, чтобы наглядно показать объективную необходимость, побуждающую каждую из сторон учувствовать в производственном процессе.

Человек не может жить без питания, жилища, одежды и лекарственных средств, поэтому первый и самый важный мотив, побуждающий его принимать участие в процессе производства - обеспечить свое выживание в природе. После того, как такое выживание обеспеченно, оставшиеся средства вероятнее всего будут направлены на развитие, т.е. на улучшение его существования, как материального, так и духовного.

В отличии от наемного работника, собственник средств производства в первую очередь должен обеспечить восстановление авансированного капитала, так как он служит источником его дохода. Только потом обеспечить себя и семью средствами для выживания и уже потом развивать бизнес. Такая необходимость существенно отличает капиталиста от наемного работника, является причиной уязвимости в период экономических кризисов.

Согласно данной схемы, государству требуется средства на еще большее количество задач, прежде чем оно направит ресурсы на свое развитие. В первую очередь государство должно обеспечить функционирование общественных институтов (обеспечить деятельность власти, на минимальном уровне организовать образование, здравоохранение, обеспечить охрану границ и т.п.), так как без этого государство не сможет существовать. Второй пункт, изложен как «компенсация жизненных потерь части общества». Под такой формулировкой нами понимается необходимость поддержки населения не имеющего возможности трудиться (пенсионеры, инвалиды и другие социально незащищенные части общества). Далее государству необходимо обеспечить инфраструктуру (связь, дороги и иное транспортное сообщение и т.п.). Только после определенных установленных расходов на первые три позиции, возможно дальнейшее развитие государства.

На наш взгляд, основные противоречия в отношениях между наемным работником и собственником средств производства в вопросах распределения результатов деятельности находятся в области определения минимальных порогов необходимых для удовлетворения, представленных выше мотивов. Так, позиция государства на необходимый прожиточный минимум и взгляды наемных работников могут существенно различаться. Также может иметь различия позиция собственника 
средств производства и позиция наемного рабочего на минимальный порог оплаты труда. Экономические основы таких противоречий в отношениях между сторонами-участниками производственного процесса необходимо искать в организации процесса производства благ, а также в последующим их распределении. Рассмотрение процесса производства как экономической категории сложная теоретическая и практическая задача, которая не является предметом данной работы, поэтому мы остановимся лишь на вышеизложенном.

Как видим, причина возникающих противоречий в вопросах распределения произведенных благ между наемным работником и собственником средств производства находится в границах поиска баланса распределения долей произведенного блага основанного на различиях в мотивах участия в производственном процессе. Иными словами, собственник средств производства должен обеспечить восстановление потраченного капитала и только потом обеспечить личные нужды, а наемный работник обеспечивает в первую очередь траты на свое существование.

Практическая реализация механизмов собственника средств производства, направленных на обеспечение своей жизнедеятельности в отличии от наемного работника всегда связана с применением капитала. В свою очередь, применение капитала также всегда оказывает влияние на те или иные сферы существования общества, то есть применение капитала формирует трансформацию. Изменения возникающие в процессе применения капитала влияют, в том числе на массы людей, которые в свою очередь не хотят меняться, так как любое изменение это затраты энергии, временные затраты связанные с необходимостью совершенствоваться, изменять себя под другие реалии, которые приносит капитал.

Обобщая вышеизложенное, необходимо отметить, что в современном мире, мире всевозрастающих технологий и развивающейся науки, капитал не может возрастать без постоянных изменений, что неминуемо тянет за собой весь спектр общественных трансформаций. Общественные устои, образ жизни, традиции - все это не может мгновенно трансформироваться, так как является результатом многовекового общественного существования. В настоящий период капитал стремиться к высоте технологий и постоянному прогрессу в производстве, таковы реалии развития. Вот и получается, что капиталист со своим капиталом вынужден функционировать на грани цейтнота, постоянно быть в поиске новых форм дальнейшего развития, иначе он потеряет капитал, а наемный работник не заинтересован в такой быстрой смене формаций, так как уже упоминалось выше, такая смена требует от него личных и (или) в конечном итоге финансовых затрат. Такая ситуация и порождает противостояние(противоречие) между собственником средств производства и наемным работником, одним развитие приносит доход, другим необходимость постоянно трансформироваться под меняющиеся реалии, или говоря иначе, одни меняют мир, другие вынуждены меняться, принимая предлагаемые условия - вот, на наш взгляд, сущность противоречия во взаимоотношениях собственников средств производства и наемных рабочих.

\section{ЛИТЕРАТУРА}

1. Аитова Г.Ш., Бузгалина А. В., Булавка-Бузгалина Л. А. Критический марксизм: поколение пехт. Новый взгляд на отчуждение, глобализацию и Россию. М.: ЛЕНАНД, 2014. - 392 c.

2. Вебер М. Избранное. Образ общества. М.: Издательство «Юрист», 1994.704 с.

3. Григорьева 0.Ю., Попов Б. А. Переход к рынку: борьба мнений. - М.: Наука, 1993. - 192 с.

4. Менгер К. Избранные работы. М.: Издательский дом «Территория будущего», 2005. - 496 с.

5. К Кларк Дж. Б. Распределение богатства. М-Л.: Государственное социально-экономическое издательство, 1934. — 299 с.

6. Сафиуллин Л. Н. Общественное благосостояние в условиях неоднородности рынков. Казань.: Изд-во Казанского университета, 2006. - 296 с.

7. Струмилин С. Г. Статистико-экономические очерки. М.: Государственное статистическое издательство, 1958 г. - 735 с.

8. Шумпетер Й. А. История экономического анализа. 1,2,3 Т. С-П.: Издательство «экономическая школа», 2001. - 1664 с.

9. Есть ли будущее у капитализма? Сб. статей И. Валлерстайна, Р. Коллинза, М. Манна, Г. Дерлугьяна, К. Калхуна / пер. в англ. под ред. Г. Дерлугьяна.- М.: Изд-во Института Гайдара, 2015.-320 с. 